\title{
Agraffectomy after low rectal stapling procedures for hemorrhoids and rectocele
}

\author{
M. Pescatori · G. Gagliardi
}

Received: 28 June 2011/Accepted: 28 June 2011/Published online: 12 July 2011

(C) Springer-Verlag 2011

While the majority of patients after procedure for prolapse and hemorrhoids (PPH) have an uneventful recovery, there is a minority who will experience chronic complications, such as inflammation, chronic pain and defecatory disorders. The same is also true for stapled transanal rectal resection (STARR) carried out for obstructed defecation. Some of these complications are believed to occur because of retained staples.

The merit of the review by Petersen et al. [1] is that the authors recall the attention of the surgical community to the problem of retained staples following $\mathrm{PPH}$ and STARR.

Interestingly, a recent study reported that most surgeons who performed PPH informed their patients that staples would be shed within 3 weeks to 3 months after surgery. Instead, all patients in this study who had a plain x-ray 1 week to 5 years after surgery were shown to have retained staples [2]. In another study, $20 \%$ of reinterventions carried out following $\mathrm{PPH}$ were performed due to symptomatic retained staples [3].

What are the symptoms caused by retention of staples? Chronic bleeding, rectal stricture and penile trauma during sexual intercourse may be related to retained staples and require staple removal, with clinical relief of symptoms. But the aforementioned complications are relatively rare following PPH and STARR. Instead, postoperative painful defecation is more frequent, ranging between 2 and $20 \%$

\footnotetext{
M. Pescatori $(\bowtie)$

Rome, Italy

e-mail: ucpclub@virgilio.it

G. Gagliardi

New Orleans, LA, USA

e-mail: gagliarg@yahoo.com
}

[4]. Unfortunately, pain is likely to affect the quality of life in these patients.

Therefore, the crucial question is: Is agraffectomy indicated to relieve severe chronic pain after PPH and STARR? Despite encouraging occasional reports [5], the current review concludes that there is not enough evidence to justify agraffectomy when aimed at relieving chronic postoperative pain. This conclusion is mainly based on the paucity of data and the lack of a homogeneous patient population. The first problem that the authors encountered is in the definition of agraffectomy that includes disparate procedures, from the removal of single staples through a proctoscope to the most radical which is the removal of the entire anastomotic ring with all the associated fibrosis followed by manual anastomosis between healthy tissues. Moreover, pain after transanal stapled procedures may be multifactorial and secondary not only to inflammation and fibrosis but also to underlying functional and psychological disorders often ignored in the evaluation of these patients. The authors quote a theory postulated by Cheetham et al. [6] who attributed chronic pain after PPH to fibrosis causing chronic stimulation of the somatic sensory nerves of the levator ani muscles. Whether the central or peripheral somatic or visceral component is prevalent in the etiology of chronic postoperative proctalgia is still unknown. As the authors conclude, prospective studies are needed in which patients undergo thorough pre- and postoperative evaluation. Until then, the benefits of this procedure will remain uncertain, and it will remain indicated as a "last alternative."

Meanwhile, caution is required in using a transanal stapling procedure when dealing with hemorrhoids and obstructed defecation, which may be managed with alternative conservative and surgical measures without the risk of retained staples. 


\section{References}

1. Petersen S, Jongen J, Schwenk W (2011) Agraffectomy after low rectal stapling procedures for hemorrhoids and rectocele. Tech Coloproctol 15(3). doi:10.1007/s10151-011-0704-6

2. Garg P, Lakhtaria P, Song J, Ismail M (2010) Proctitis due to retained staples after stapler hemorrhoidopexy and a review of literature. Int J Colorectal Dis 25:289-290

3. Brusciano L, Ayabaca SM, Pescatori M et al (2004) Reinterventions after complicated or failed stapled hemorrhoidopexy. Dis Colon Rectum 47:1846-1851
4. Pescatori M, Gagliardi G (2008) Postoperative complications after procedure for prolapsed hemorrhoids $(\mathrm{PPH})$ and stapled transanal rectal resection (STARR) procedures. Tech Coloproctol 12:7-19

5. Wunderlich M, Freitas A, Langmayr J, Tentschert G (2006) Proktologia (Suppl) 83

6. Cheetham MJ, Mortensen NJ, Nystrom PO, Kamm MA, Phillips RK (2000) Persistent pain and faecal urgency after stapled haemorrhoidectomy. Lancet 356:730-733 